\title{
Campus Teaching Awards, Academic Year 2015-2016
}

A

PSA is pleased to recognize the recipients of campus-wide and departmental awards for teaching excellence during the 2015-2016 academic year. The campus teaching award winners were recognized at the APSA Annual Meeting in Philadelphia, Pennsylvania 1 - as part of the Reception Honoring Teaching, which was co-sponsored by Pi Sigma Alpha, the Political Science Education Section, the Committee on the Status of Community Colleges, and the Committee on Teaching and Learning. (Photos appear above recipient's name and institution.)

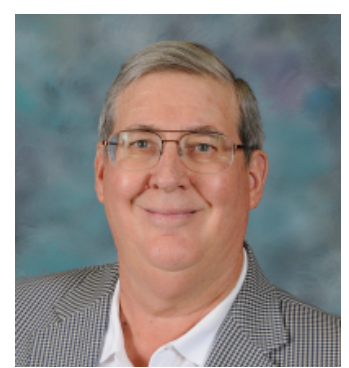

Hal Bass, Ouachita Baptist University, Most Inspirational Faculty Member

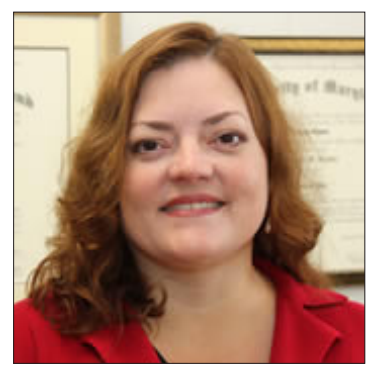

Mitchell Brown, Auburn University, Student Government Association Outstanding Faculty Member, College of Liberal Arts

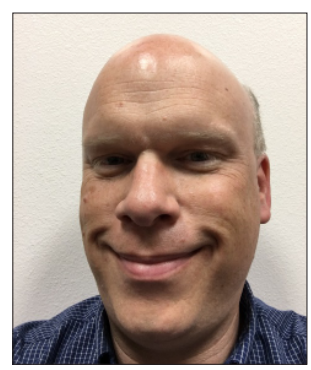

Christopher Butler, University of New Mexico, Outstanding Teacher of the Year Award

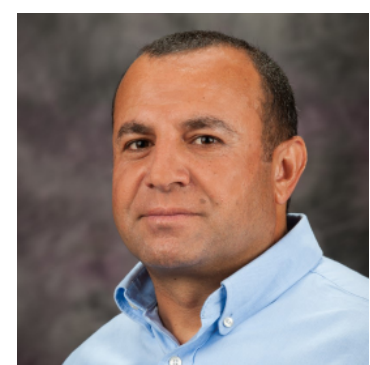

Sabri Ciftci, Kansas State University, 2016 Stamey Award for Undergraduate Teaching

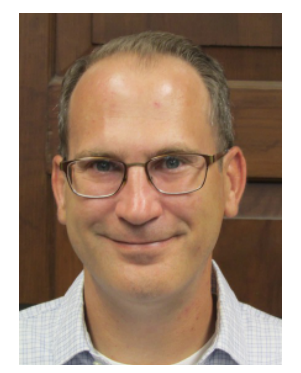

Joe Clare, Louisiana State University, Tiger Athletic Foundation Outstanding Undergraduate Teaching Award

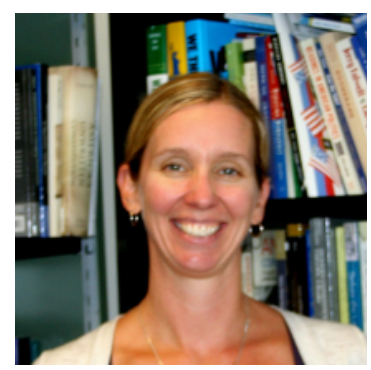

Courtenay Daum, Colorado State University, Ann Gill Excellence in Teaching Award

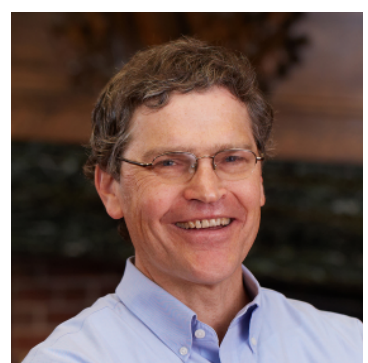

Matthew Dickinson, Middlebury College, The Marjorie Lamberti Faculty Appreciation Award

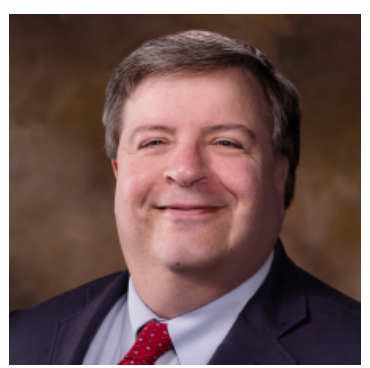

Andrew Dowdle, University of Arkansas, Sponsored Student Programs Outstanding Faculty Member

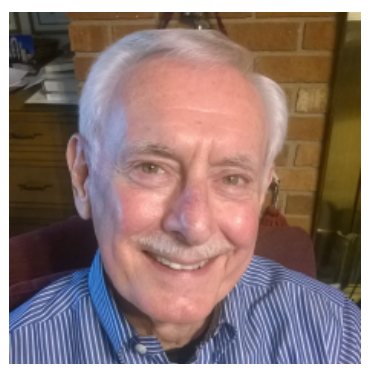

Joe Dunn, Converse College, Cato Award for Faculty Excellence 


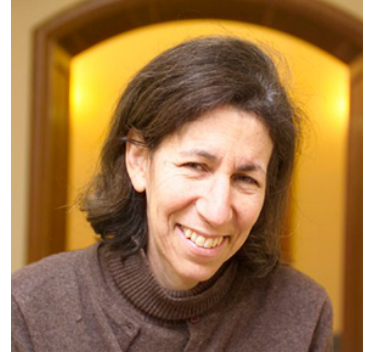

Mary Fainsod Katzenstein, Cornell University, Merrill Presidential Scholar Recognition

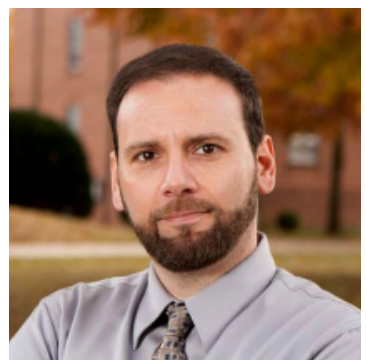

Joseph Fitsanakis, Coastal Carolina University, Apple Award for Outstanding Teaching

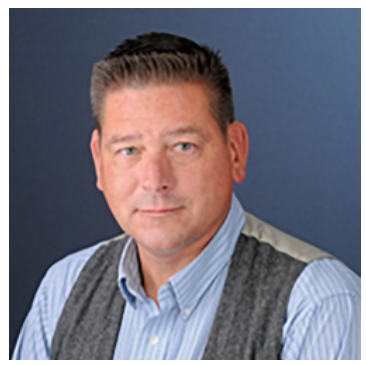

Donald Haider-Markel, University of Kansas, 2016 Byron A. Alexander Outstanding Graduate Mentor Award

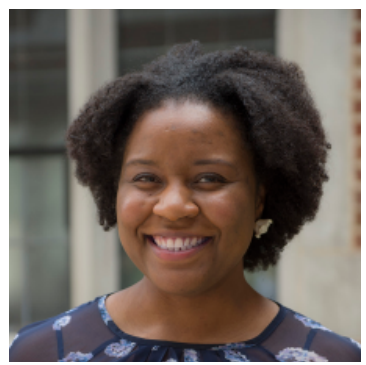

Jaira Harrington, Wake Forest University, The Wayne C. Booth Graduate Student Prize for Excellence in Teaching (University of Chicago)

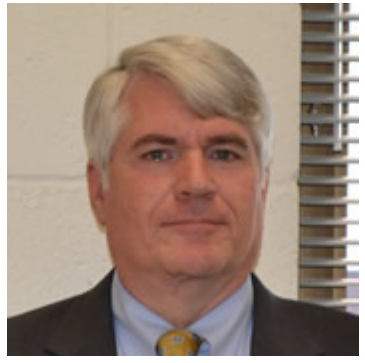

Murray Jardine, Auburn University, Daniel T. Nelson Outstanding Political Science Professor

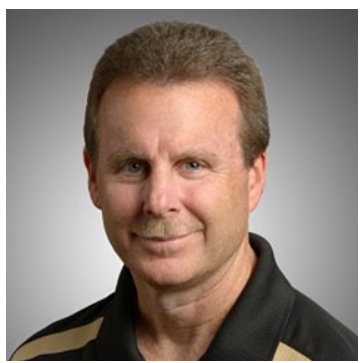

Aubrey Jewett, University of Central Florida, Excellence in Undergraduate Teaching

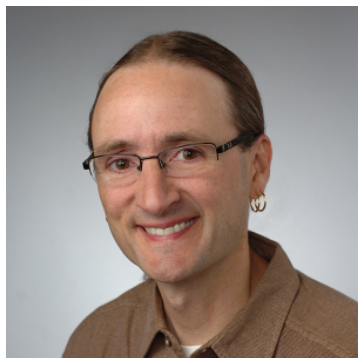

Thomas Keck, Syracuse University, Excellence in Graduate Education Faculty Recognition Award

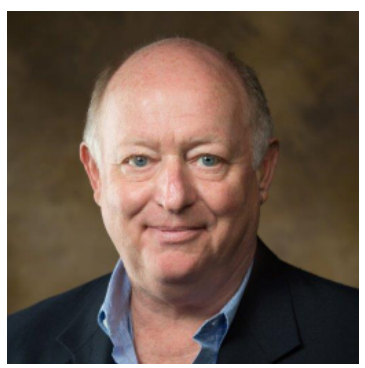

Brinck Kerr, University of Arkansas, Fulbright College Master Teacher

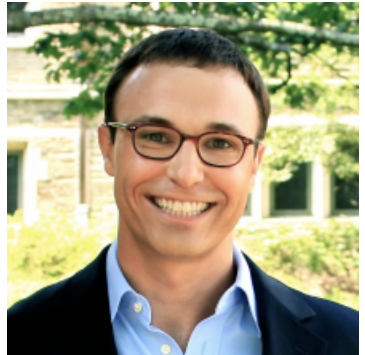

Michael Lamb, University of Oxford, Humanities Teaching Excellence Award

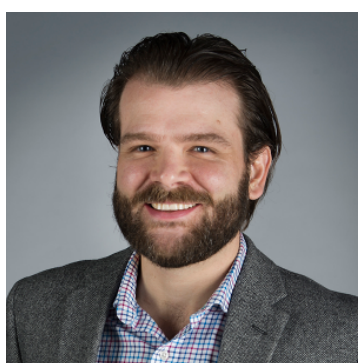

Matthew LeRiche, Memorial University of Newfoundland, President's Award for Outstanding Teaching

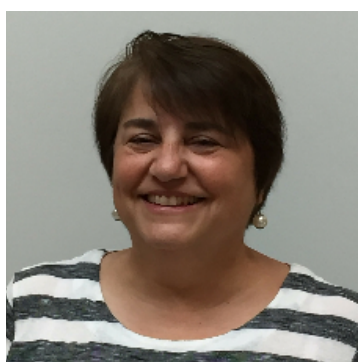

Mona Lyne, University of Missouri-Kansas City, College of Arts \& Sciences Alumni Outstanding Teaching Award

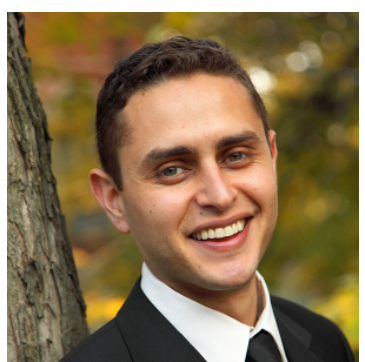

Mark Fathi Massoud, University of California, Santa Cruz, Excellence in Teaching Award 


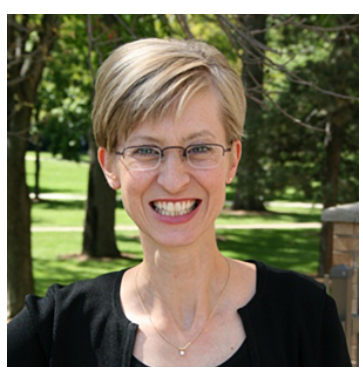

Melissa Miller, Bowling Green State University, 2016 Master Teacher Award

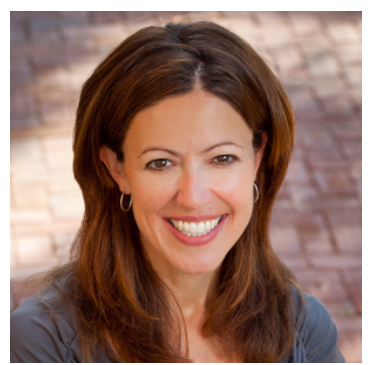

Janine Parry, University of Arkansas, Imhoff Award for Outstanding Teaching and Mentorship

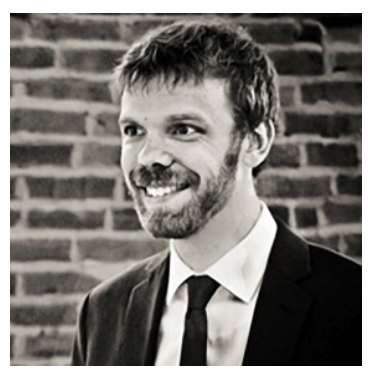

Joshua Potter, Louisiana State University, Tiger Athletic Foundation Undergraduate Teaching Award

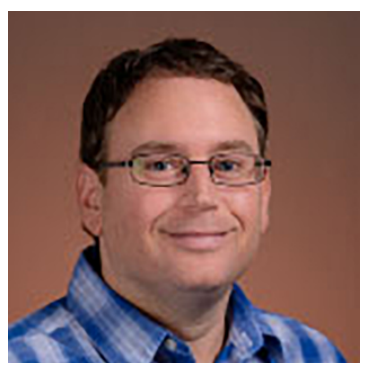

Charles Ripley, Arizona State University, Michael Mitchell Best Teaching Award

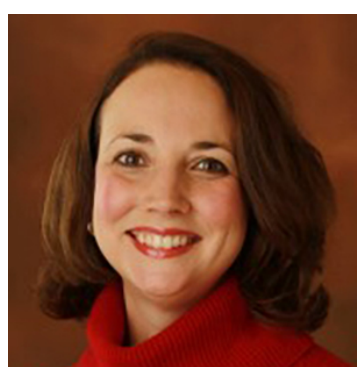

Carrie Russell, Vanderbilt University, Harriet S. Gilliam Award for Excellence in Teaching

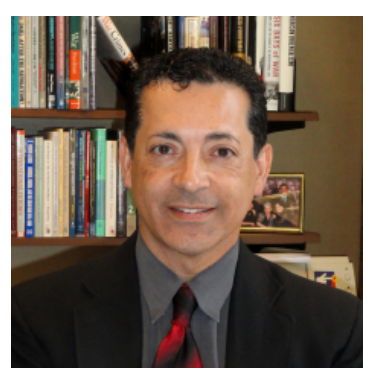

Houman Sadri, University of Central Florida, Teaching Incentive Award

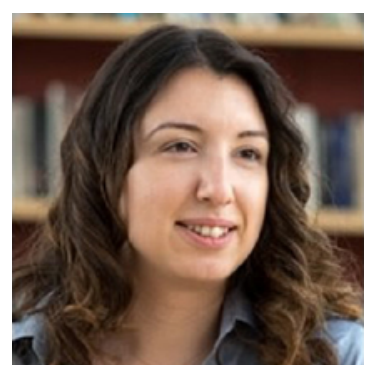

Nukhet Sandal, Ohio University, Jeanette G. Grasselli Brown Teaching Award in the Social Sciences

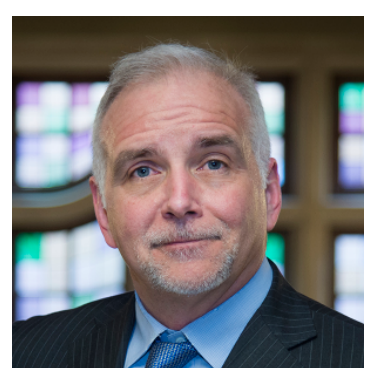

Keith Shimko, Purdue University, Charles B. Murphy Award for Outstanding Undergraduate Teaching

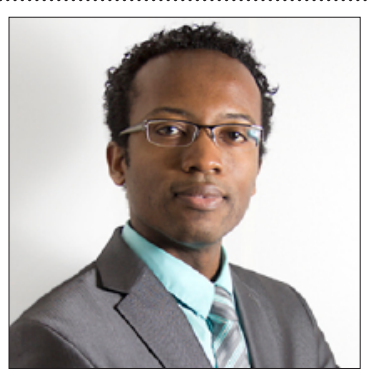

Landry Signé, University of Alaska Anchorage, Order of Excellence

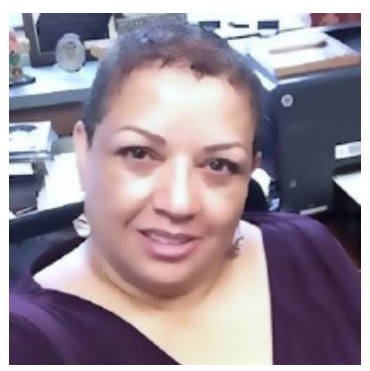

Andrea Simpson, University of Richmond, Distinguished Educator Award

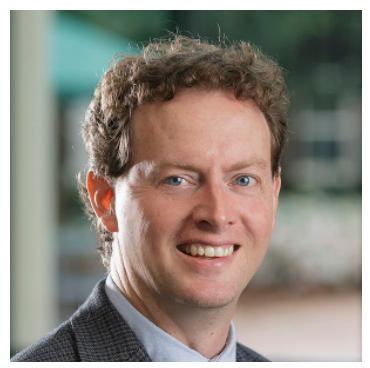

Benjamin Storey, Furman University, Alester G. Furman Jr. and Janie Earle Furman Meritorious Teaching Award

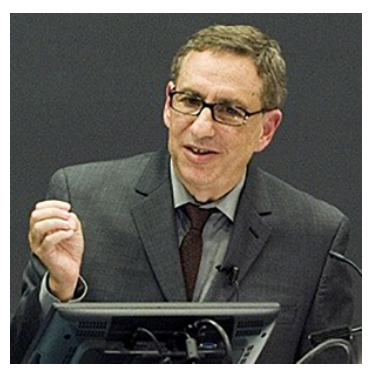

Jeffrey Tulis, University of Texas at Austin, Outstanding Faculty Award 
The Teacher: Campus Teaching Awards 2014-2015

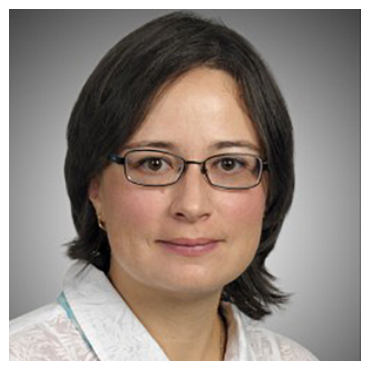

Anca Turcu, University of Central Florida, Teaching Incentive Program Award

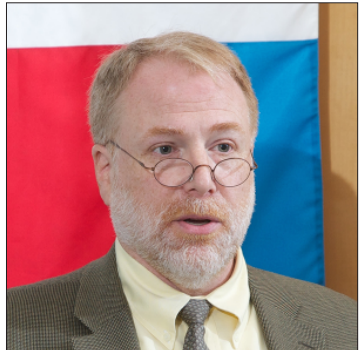

Marc Weiner, Rutgers University-New Brunswick, Graduate Faculty Teaching Award

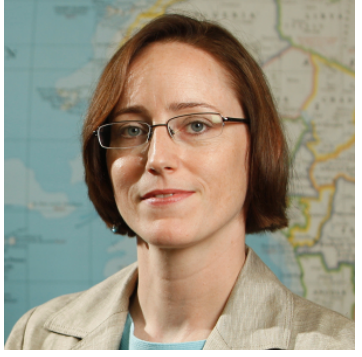

Elizabeth Zechmeister, Vanderbilt University, Award for Excellence in Graduate Teaching 